\title{
XYLAZINE-KETAMINE ANAESTHESIA; COMPARATIVE STUDIES IN MALE AND FEMALE CANE RATS (THRYONOMYS SWINDERIANUS)
}

\author{
OLATUNJI-AKIOYE Aa, OJIAKA H. Na, SAMUEL E. S ${ }^{\text {* }}$ \\ aDepartment of Veterinary Reproduction and Surgery, University of Ibadan, Ibadan, Nigeria, ${ }^{\mathrm{b} D e p a r t m e n t}$ of Veterinary Physiology, \\ Biochemistry and Pharmacology, University of Ibadan, Ibadan, Nigeria \\ Email: development4sure@yahoo.com
}

Received: 09 Apr 2016 Revised and Accepted: 27 0ct 2016

\section{ABSTRACT}

Objective: Domestication of the Cane rats is on-going globally and might replace the conventional rodents used in biomedical research in future. However, the paucity of information on adequate anaesthesia vis-a-vis xylazine-ketamine drug combination in the male and female Cane rats warranted this study.

Methods: Six adult Cane rats $\{1.8 \pm 0.7 \mathrm{~kg}$ body weights (bwt.) $\}$ assigned into group A (Female) and group B (Male) of three rats each was used for the study. Each animal was premedicated with atropine sulphate $(0.05 \mathrm{mg} / \mathrm{kg}$ bwt $)$, and later administered xylazine $(10 \mathrm{mg} / \mathrm{kg}$ bwt $)$ and ketamine (100 mg/kg bwt) intramuscularly. Meanwhile, anaesthetic characteristics and physiologic indices of anaesthesia were monitored.

Results: Results obtained showed that the physiologic indices; open eyelids, smooth induction and recovery, skeletal muscle relaxation and somatic analgesia were observed in all the animals, however, the anaesthetic indices; time to induction, time to standing, duration of analgesia and duration of recumbency showed marked sex variations. The mean values for the duration of analgesia and recumbency were significantly elevated $(\mathrm{P}<0.05)$ in group B as compared with group A. Similar trend was seen for time to standing, but, it was non-significant $(\mathrm{P}>005)$. However, time to induction mean value for group A was non-significantly increased $(\mathrm{P}>005)$ when compared with group $\mathrm{B}$. The heart rate, respiratory rate and rectal temperature mean values decreased in both groups non-significantly $(\mathrm{P}>0.05)$.

Conclusion: Conclusively, the xylazine-ketamine combination produced anaesthesia in Cane rat and the combination is more tolerated in the male Cane rats than the female Cane rats.

Keywords: African Cane rats, Xylaxine, Ketamine, Anaesthesia

(C) 2017 The Authors. Published by Innovare Academic Sciences Pvt Ltd. This is an open access article under the CC BY license (http://creativecommons.org/licenses/by/4. 0/A

DOI: http://dx.doi.org/10.22159/ijpps.2017v9i1.12140

\section{INTRODUCTION}

The Cane rat popularly known as 'Grasscutter' (Thryonomys swinderianus) is a natural hystricomorph rodent that is peculiar to subtropical region especially Nigeria [1]. Cane rats can grow to nearly $2 \mathrm{ft}(0.61 \mathrm{~m})$ in length and weigh a little less than $19 \mathrm{lb}(8.6 \mathrm{~kg})$. It has rounded ears, a short nose, and coarse, bristly hair. The fur reflects the general colour of the animal with brownish colour from base to middle of the fur while the upper fur appears light yellow to red, the combination of which gives the animal brownish yellow/red colouration [2].

Within the West African sub-region, Cane rats serve as a source of protein [3-5] and it was demonstrated that the animal could be kept in captivity [3]. This was followed by studies on several aspects of the biology and ecology of the animal [6-8]. Grasscutter is the second largest rodent in Africa after porcupine [9]. The Cane rat by virtue of its larger size might replace the conventional rats and mice in biomedical laboratories research. Therefore, it is reasonable to anticipate an upsurge in demand for clinical procedures necessitating the use of anaesthetics on Cane rat in the nearest future.

An ideal anaesthetic for laboratory mammals has been described [10] and a number of anaesthetics have been used in rodents. However, they produced several undesirable effects like hyperglycemia with osmotic diuresis observed with xylazine use in most species [11]. An alternative to hypnorm and diazepam is xylazine and ketamine which has been reported to provide good anaesthesia in most animal species including rodent [12]

This drug combination should be of interest as it avoids the use of facemasks, vaporiser, and volatile anaesthetics. However, there is a paucity of scientific information on the use of xylazine and ketamine in the Cane rat. As a result of this, we investigated and compared the anaesthetic properties of xylazine-ketamine drug combination between male and female Cane rats.

\section{MATERIALS AND METHODS}

\section{Chemical reagents}

Atropine sulphate (Atocan: Shuguang Pharmaceutical Company Ltd Shanxi, China.) was supplied as a $1 \mathrm{mg}$ per ml solution for injection in $1 \mathrm{ml}$ ampoule. Xylazine hydrochloride (Rompun: Kepro, Holland.) was supplied as a $20 \mathrm{mg}$ per $\mathrm{ml}$ solution for injection in $25 \mathrm{ml}$ multidose vial while ketamine hydrochloride (Vetalar: Rotex Edia Tritta, Germany.) was supplied as a $50 \mathrm{mg}$ per ml solution for injection in $10 \mathrm{ml}$ multidose vial.

Experimental animals and protocol

Six adult Cane rats $\{(1.8 \pm 0.7 \mathrm{~kg}$ body weights (bwt.) $\}$ that were assigned into group A (Female) and group B (Male) of three rats each was used for the study. Animals were obtained from the experimental animal house of the Department of Veterinary Physiology, Biochemistry and Pharmacology, Faculty of Veterinary Medicine, University of Ibadan, Ibadan, Nigeria and were handled in conformity with the guide for the care and use of laboratory animals [13]. All the experimental procedures were approved by the institutional animal ethical committee with certificate no: ethic/14/02/05.

The animals were healthy and kept in steel laboratory cages $(60 \times$ $60 \times 50 \mathrm{~cm}$ ). All animals were kept under controlled conditions of temperature $\left(25 \pm 2{ }^{\circ} \mathrm{C}\right)$, relative humidity $(50 \pm 15 \%)$ and normal photoperiod (12 h light and $12 \mathrm{~h}$ dark). The Cane rats were separately caged according to their sex and were fed on a standard Cane rat diet; Cane grass, maize, and feed concentrate (Kesmac Feed Industry, Ibadan, Oyo State, Nigeria) and given water ad libitum. The rats were restrained by an assistant and intramuscular injection was 
introduced into proposed site and aspirated to confirm that no blood vessels were penetrated. Each Cane rat was premedicated with atropine sulphate $(0.05 \mathrm{mg} / \mathrm{kg}$ bwt $)$, and later administered xylazine $(10 \mathrm{mg} / \mathrm{kg} \mathrm{bwt})$ and ketamine $(100 \mathrm{mg} / \mathrm{kg} \mathrm{bwt})$ intramuscularly using $1 \mathrm{ml}$ syringe $27 \mathrm{G}$ [12].

\section{Assessment}

After the administration of the drug mixture, each Cane rat was observed for evidence of vomiting or regurgitation, salivation, apneustic breathing, muscle tremor or spontaneous movements and open eyelids. In addition, the quality of induction and recovery, as well as skeletal muscle relaxation and analgesia were assessed. Analgesia was observed present if the pricking or pinching of the anaesthetized animal's feet, stimulated no gross muscular movement.

\section{Measurements}

For each anaesthetized Cane rat, respiratory and heart rates were recorded immediately following the loss of the righting reflex, and then at 10 min intervals over a 90 min period. Respiratory rates were determined through counting the number of thoracic and/or abdominal movements. Heart rates were determined using a precordial stethoscope placed on the left side of the animal's chest. Rectal temperature was measured with the aid of a digital electronic thermometer at the predetermined time points.

\section{CALCULATION}

Induction time, duration of analgesia, duration of recumbence, and time to standing were calculated in minutes for each anaesthetized Cane rat. "Induction time" was defined as a period of administration of the drug mixture to loss of righting reflex. "Duration of analgesia" was defined as a period of loss of righting reflex to return of righting reflex. "Duration of recumbence" was also the period between the losses of righting reflex to the period when the animal came to sterna. "Time to standing" was defined as the period between time to sterna and when the animal was fully ambulatory and clinically normal.

\section{Statistical analysis}

Data obtained were recorded and analyzed using student t-test [14]. The difference of the means was considered significant at $\mathrm{P}<0.05$.

\section{RESULTS}

Physiological effects of xylazine-ketamine anaesthesia on Cane rat

The physiological indices of xylazine-ketamine anaesthesia in the Cane rat are shown (table 1). It was discovered that none of the anaesthetized animals vomited or regurgitated, however, apart from open eyelids, other notable dissociative anaesthetic features such as apneustic breathing, muscle tremor, and spontaneous limb movement were not observed. The drug combination appeared to produce surgical anaesthesia characterised by smooth induction and recovery, skeletal muscle relaxation and somatic analgesia. Throughout this period there was no salvation or urination observed in the rats.

\section{Anaesthetic indices of xylazine-ketamine combination in cane rat}

The anaesthetic indices of the xylazine-ketamine drug combination in the Cane rats are shown (table 2). The time to induction, duration of analgesia, duration of recumbence, and time to standing were observed. These anaesthetic indices showed marked sex variations especially the duration of analgesia and recumbence; these indices were significantly elevated $(\mathrm{P}<0.05)$ in male Cane rats as compared to the female Cane rats.

Table 1: Physiological effects of xylazine-ketamine anaesthesia

\begin{tabular}{|c|c|c|c|c|c|c|}
\hline \multirow[t]{2}{*}{ Effects } & \multicolumn{3}{|c|}{ Group A } & \multicolumn{3}{|c|}{ Group B } \\
\hline & A1 & A2 & A3 & B1 & B2 & B3 \\
\hline Rough induction & - & - & - & - & - & - \\
\hline Smooth induction & + & + & + & + & + & + \\
\hline Vomiting/regurgitation & - & - & - & - & - & - \\
\hline Apneustic breathing & - & - & - & - & - & - \\
\hline Muscle tremors & - & - & - & - & - & - \\
\hline Spontaneous movement & - & - & - & - & - & - \\
\hline Muscle relaxation & + & + & + & + & + & + \\
\hline Open eyelids & + & + & + & + & + & + \\
\hline Salivation & - & - & - & - & - & - \\
\hline Analgesia & + & + & + & + & + & + \\
\hline Rough recover & - & - & - & - & - & - \\
\hline Smooth recovery & + & + & + & + & + & + \\
\hline Urination & - & - & - & - & - & - \\
\hline Shivering & - & - & - & - & - & - \\
\hline
\end{tabular}

-not observed in the anaesthetized Cane rat,+observed in the anaesthetized Cane rat

Table 2: Anaesthetic indices of xylazine-ketamine combination

\begin{tabular}{lllll}
\hline Parameters (min) & Time to induction & Duration of analgesia & Duration of recumbency & Time to standing \\
\hline Group A & $2.7 \pm 0.3333^{\mathrm{a}}$ & $37.0 \pm 1.15^{\mathrm{a}}$ & $111 \pm 5.86^{\mathrm{a}}$ & $4.0 \pm 1.00^{\mathrm{a}}$ \\
Group B & $2.0 \pm 0.00^{\mathrm{b}}$ & $70.7 \pm 10.4^{\mathrm{a}}$ & $145 \pm 8.09^{\mathrm{a}}$ & $10.0 \pm 2.65^{\mathrm{b}}$ \\
\hline
\end{tabular}

a,bvalues are expressed as mean \pm standard error of mean (SEM) and means with the same superscript within columns are significantly different $(\mathrm{P}<0.05), \mathrm{N}=3$.

Fig. 1 shows the mean heart rate of anaesthetized Cane rats. This parameter decreased from $131 \pm 4.81$ beats/minutes to $116 \pm 4.00$ beats/minutes and $125 \pm 9.33$ beats/minutes to $113 \pm 5.33$ beats/ minutes for the female and male Cane rats respectively and these did not approach the initial value at the end of the observation period of the 90th-minute interval. However, there was no significant difference between their mean values $(\mathrm{P}>0.05)$.
In addition, the mean values for the respiratory rates of the anaesthetized Cane rats decreased from $45.3 \pm 2.67$ breaths/minute to $42.7 \pm 1.33$ breaths/minute and $48.0 \pm 4.62$ breaths/minute to $30.7 \pm 5.81$ breaths/minutes for the female and male Cane rats respectively at the 90th minute interval and also, the initial value was not approached at the end of the observation period (fig. 2). However, there was no significant difference between their mean values $(\mathrm{P}>0.05)$. 


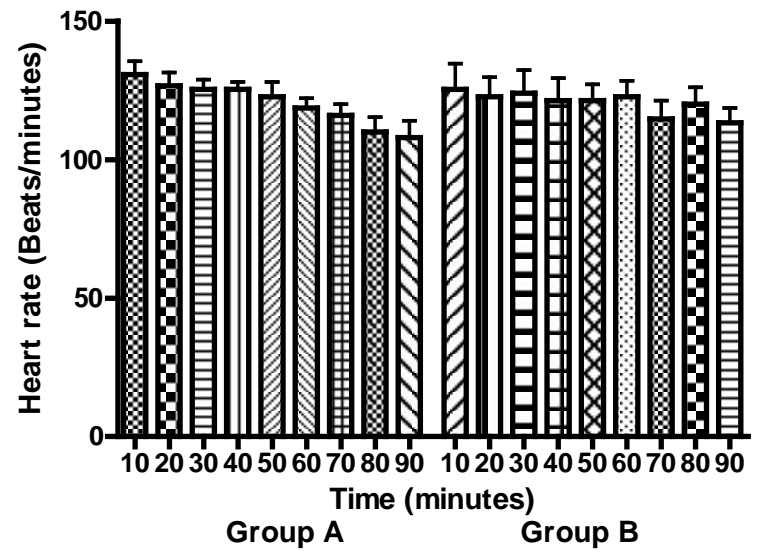

Fig. 1: Heart rate of cane rat anaesthetized with xylazineketamine. Values are expressed as mean $\pm S E M, n=3$

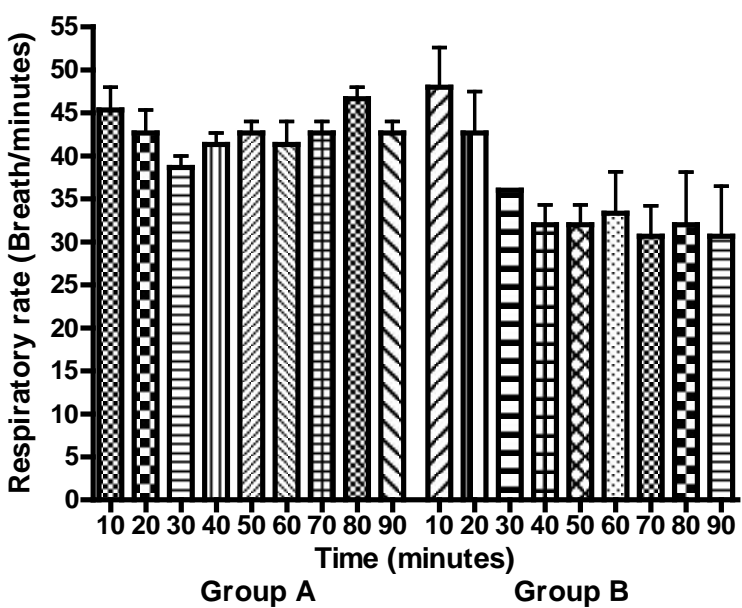

Fig. 2: Respiratory rates of Cane rat anaesthetized with xylazine-ketamine. Values are expressed as mean $\pm S E M, n=3$

Fig. 3 shows the mean rectal temperature of anaesthetized Cane rats. This variable decreased from the initial mean values of $36.7 \pm 0.78$ and $37.0 \pm 0.29{ }^{\circ} \mathrm{C}$ to final mean values $34.2 \pm 0.46$ and $34.7 \pm 0.75{ }^{\circ} \mathrm{C}$ for the female and male Cane rats respectively at the 90th-minute interval. The anaesthetized Cane rats showed slightly constant variations in rectal temperature between groups.

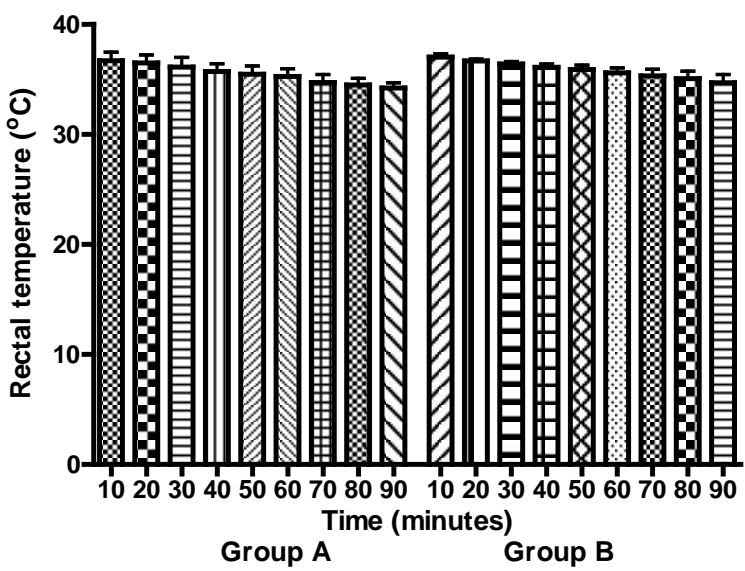

Fig. 3: Rectal temperature of Cane rats anaesthetized with xylazine-ketamine. Values are expressed as mean $\pm S E M, n=3$

\section{DISCUSSION}

Atropine sulphate was administered as a premedicant in form of a drying agent, because salivary and bronchial secretions have been known to increase by both xylazine [15] and ketamine [16] administration. Since small mammals are known to have tiny air ways, the presence of even a small amount of secretion could result into obstruction of respiration.

The combination of the two drugs; ketamine and xylazine in addition to the earlier administered atropine, gave the advantage of counteracting the xylazine induced bradycardia through the cardio stimulating effect of ketamine [16]. The injection of the drug combination spared the Cane rats the discomfort that could occur with multiple needle punctures. Emesis which is a common side effect of xylazine administration did not occur in the Cane rats even though they were not starved prior to administration of the drug combination and this has proven that it is unnecessary to withhold food and water before induction of anaesthesia since vomiting on induction or recovery does not occur in any of the small rodents [12].

The rapid onset of induction that is non-significant and almost similar between the groups suggests that there was the rapid absorption of the drugs from the intramuscular route.

The drug combination produces surgical anaesthesia that was free of the rigidity that occurs in the use of ketamine alone. Skeletal muscle relaxation was positive (see table 1 ) and analgesia was significantly higher in the male Cane rats (see table 2). In theory, these conditions would appear to permit major surgical procedures to be carried out in the absence of spasmodic muscle contraction (table 1) but in practices, it involves the elicitation of pain. The clinical assessment of intensity of pain (in respect to level of analgesia) is based on signs exhibited by the animal that is interpreted as pain, and this involves observation and perception $[17,18]$.

In this study, assessment of pain in these animals involve pedal reflex (withdrawal of foot in response to stimulation) evoked by threshold level, noxious stimulus without injury to tissue. The Cane rats never responded to this stimulus until about $37.0 \mathrm{~min}$ and 70.7 min for the female and male groups respectively. This shows that the surgical procedures could be carried out in Cane rat within this time limit before pain is being elicited using this drug combination.

There was a positive result for open eyelid (see table 1) in both groups, and this could be linked to the vagolytic action of atropine sulphate used in the anaesthetic protocol [19] and so in species where corneal reflex is lost for prolonged periods, drying of the cornea may occur unless the eyes are filled with a bland ophthalmic ointment as a preventive measure [12].

It was observed that neither of the anaesthetized Cane rats groups urinated contrary to the hyperglycaemia with osmotic diuresis observed with xylazine use in most animal species $[11,20]$. A similar diuresis had been observed by Flecknell [12] during xylazineketamine administration in rats and mice and thus advised against their use in animals that are dehydrated, weak or in shock. This may relate to species differences or other unknown factors.

Marked increase in respiratory and heart rate has been reported to be caused by fear and apprehension in the pre-anaesthetic period and due to a lightening in the level of anaesthesia [12]. These are likely to be more profound in semi-wild and wild Cane rats. Although, standard normal ranges for respiratory rate, heart rate and body temperature could be used as baseline values, but these are yet to be determined for Cane rats. And as a result, trends rather than absolute values were only available for assessment. It was furthermore decided to monitor these physiological variables during the first $90 \mathrm{~min}$ of anaesthesia with the assumption that this period of time could be the most critical in the whole anaesthetic process.

The mean heart rate of the Cane rats in this study decreased during anaesthesia, but it was not significant $(\mathrm{P}>0.05)$ between the groups. This could be related to the actions of the drug components of the mixture. This study is in support of the work of Flecknell [12] that state that xylazine, when given alone, decreases the heart rate in most species and its administration alongside atropine as premedicant has 
been reported to cause a decrease in heart rate [21-23]. The cardio stimulatory effects induced by ketamine have been reported to be prevented by the concurrent administration of sedatives. Thus, it appears that the chronotropic action of ketamine and vagolytic action of atropine were superseded by the bradycardia effect of xylazine resulting in a net decrease in heart rate. Small mammals generally have a small heart with less ventricular compliance. As a result, their hearts are less able to increase the force of contraction or stroke volume, so that the cardiac output is rate dependent [24]. An advance bradycardia should be regarded as a serious problem in small mammals. The physiological significant of the decrease in mean heart rate recorded in this study is not clear as the normal range for this variable is yet to be established for the Cane rat.

This study also showed that xylazine-ketamine combination appears to produce respiratory depression in the Cane rats even between the groups. This finding corroborates the known pharmacological action of both drugs in combination. Although, ketamine causes only moderate respiratory depression in most species [25], it is reported to produce severe respiratory depression in small rodents following its administration in high dose rates needed for surgical anaesthesia $[23,25]$. Xylazine also causes respiratory depression in many species [15]. The impact of respiratory depression on blood gases is unknown as no blood gas analysis was carried out on this study. However, according to Flecknell [12], a fall in respiratory rate to less than 40 percent of the pre-anaesthetic rate indicates impending respiratory failure. Although the recorded respiratory depression was apparently tolerated by the healthy Cane rats used in this study, animals with endemic respiratory infection with no obvious clinical signs may be at risk of respiratory failure during anaesthesia.

Mean rectal temperature decreased progressively in the anaesthetized Cane rats even in the absence of some factors known to influence heat loss from the body in the anaesthetized Cane rat as reported by Waterman [26]. Since anaesthetized small animals are more prone to the development of hypothermia, the small body weight of the Cane rats appeared to have predisposed them to increased heat losses from the body under anaesthesia. Hypothermia during anaesthesia can give rise to shivering during recovery [27]. Hypothermia can prolong recovery from anaesthesia and if severe can lead to death [12]. However, in this study, it was found out that none of the hypothermic Cane rats exhibited shivering or had delayed recovery. It might be that the recorded fall in body temperature had been slow and the cooling even, so that the resulting hypothermia was without consequence in the Cane rats.

\section{CONCLUSION}

Xylazine-ketamine drug combination appears to produce surgical anaesthesia and a fall in heart rate, respiratory rate and body temperature. The drug combination could counteract the side effect that is normally observed when used alone as none of these were seen in the Cane rats used for this study. Moreover, medical and surgical procedures of the animal require safe anaesthesia and this study suggests that xylazine-ketamine combination could be the drug combination of choice and conclusively, the combination is more tolerated in the male Cane rats than the female Cane rats.

\section{CONFLICT OF INTERESTS}

\section{Declared none}

\section{REFERENCES}

1. Adoun C, Schrage R, Yewadan LT. Lère Conférence Internationale sur l'Aulacodiculture Acquis et perspectives; 1993. p. 35-40.

2. Abioye FOA, Udah AC, Opara MN, Onyema AC, Aju PC. Adaptability study of grasscutter (Thryonomys swinderianus) in Natural and Domestic Environments: Annual Conference of Forestry Association of Nigeria; 2008. p. 155-9.

3. Asibey EOA. Wildlife as source of protein in Africa South of the Sahara. Biol Conserv 1974a;6:32-9.
4. Vos AD. Game as food. A report on its significance in Africa and Latin America. Unasylver 1978;4:2.

5. National Research Council (N. R. C). Micro-livestock: Little-Known Small Animals with a Promising Economic Future (Vietmeyer NoeLed). National Academy Press: Washington DC; 1991.

6. Asibey EOA. Some ecological and economical aspects of grasscutter Thryonomys Swinderianus (Temmick) (Mammalin Rodentia, Hystricomorpha) in Ghana. UNPBL. PhD Thesis, University of Aberdeen, UK; 1974b. p. 305.

7. Ntiamoa-Baidu Y. The ixodid parasites of the grasscutter Thryonomys swinderianus Temmick in Ghana UNPL. PhD Thesis, Edinburgh University; 1980. p. 285.

8. Ajayi SS. Wildlife as a source of protein in Nigeria: some priorities for development. Nigerian Field 1971;36:115-27.

9. Mensah GA, Okoye AM. Continued harvest of the diverse Africa animal genetics resources from the wild through domestication as a strategy for sustainable use: a case of largest grasscutter (Thryonomys swinderianus). Internal Livestock Research Institute. 2005. Available from: htpp://agtrilri.Egiar.org/agtr web/index.Php? Option=com-content and task=view and id=177 and intemid. [Last accessed on 10 Mar 2016]

10. Green CJ, Halsey MJ, Precious S, Wadley-Smith B. Alphaxalonealphadolone anaesthesia in laboratory animal; 1975.

11. Saha JK, Xia J, Grondin JM, Engle SK, Jakubowski JA. Acute hyperglycemia induced by ketamine/xylazine anaesthesia in rats: mechanism and implication for preclinical models. Exp Biol Med 2005;230:777-84.

12. Flecknell PA. Laboratory animal anaesthesia. London Academic Press; 1987.

13. US, National Institute of Health. Guide for the care and use of laboratory animals. US National Institute of Health Publication; 1985. p. 23-85.

14. Steel RGD, Torrie JII. Principles and procedure of Statistics. A biometric approach. 2nd ed. McGraw-Hill, New York; 1996. p. 6-15.

15. Knight AP. Xylazine. J Am Vet Med Assoc 1980;176:454-5.

16. Wright M. Pharmacologic effect of ketamine and its use in veterinary medicine. J Am Vet Med Assoc 1982;180:1462-70.

17. Charles ES. Principles and practice of veterinary anaesthesia. In: Anticholinergics; 1987. p. 8-13.

18. Soma LR. Behavioural changes and assessment of pain in animals. Proc. $2^{\text {nd }}$ Intl Cong Vet Anes; 1985. p. 38-41.

19. Arnett BD, Brightman AH, Musselmen EE. Effect of atropine sulphate on tear production in cats when used with ketamine hydrochloride and acetylpromazine maleate. JAVMA 1984;185:214-5.

20. Green SA, Thurmon JC. Xylazine; review of its pharmacology and use in veterinary medicine. $J$ Vet Pharmacol Ther 1988;11:295-313.

21. Klide AM, Calderwood HW, Soma LR. Cardiopulmonary effects of xylazine in dog. Am J Vet Res 1975;36:931-5.

22. Hsu WH, Bellin SI, Dellman HD. Xylazine-ketamine induced anaesthesia in rats and its antagonism by yohimbine. J Am Vet Med Assoc 1986;189:1040-3.

23. Adetunji A, Oke OA, Musa A. Preliminary observations on etamine/xylazine anaesthesia in the Africa Giant Rat (Cricetomys gambianus; Waterhouse). Afr J Biomed 1999;2:91-7.

24. Friedman WF. The physiologic properties of the developing heart. Prog Cardiovas Dis 1972;15:87-111.

25. Flecknell PA. Anaesthetic and post-operative care of small mammals in practice. In Practice 1991;9:180-9.

26. Waterman A. Accidental hypothermia during anaesthesia in dogs and cats. Vet Rec 1975;96:309-13.

27. Hall LW, Clarke KW. Veterinary anaesthesia. 9th edition. London L Bailliere Tindall; 1991.

\section{How to cite this article}

- Olatunji-Akioye A, Ojiaka HN, Samuel ES. Xylazine-ketamine anaesthesia; comparative studies in male and female cane rats (Thryonomys swinderianus). Int J Pharm Pharm Sci 2017;9(1):52-55. 